\title{
METODOLOGIA DE PLANEJAMENTO DE PAISAGENS FRAGMENTADAS VISANDO A FORMAÇÃO DE CORREDORES ECOLÓGICOS
}

\author{
Mariese Cargnin Muchailh ${ }^{1}$, Carlos Vellozo Roderjan², João Batista Campos ${ }^{3}$, \\ Ayrton Luiz Torricillas Machado ${ }^{4}$, Gustavo Ribas Curcio ${ }^{5}$ \\ ${ }^{1}$ Eng ${ }^{a}$. Florestal, M. Sc., Doutoranda em Engenharia Florestal, UFPR, IAP, Curitiba, PR, Brasil - mariese@ pr.gov.br \\ ${ }^{2}$ Eng. Florestal, Dr., Depto. Ciências Florestais, UFPR, Curitiba, PR, Brasil - roderjan@ufpr.br \\ ${ }^{3}$ Eng. Agrônomo, Dr., IAP, Curitiba, PR, Brasil - redebio@wnet.com.br \\ ${ }^{4}$ Analista de Sistemas, Esp. Geoprocessamento, Curitiba, PR, Brasil - ayrtonmachado@ hotmail.com.br \\ ${ }^{5}$ Eng. Agrônomo, Dr., Embrapa Florestas, Colombo, PR, Brasil - curcio@cnpf.embrapa.br \\ Recebido para publicação: 06/03/2008 - Aceito para publicação: 28/05/2009
}

\begin{abstract}
Resumo
Objetivou-se com este estudo definir uma metodologia de planejamento que possibilite a análise da estrutura de determinada paisagem e de suas características bióticas e abióticas, para a elaboração de um zoneamento adequado do uso do solo. As principais diretrizes do estudo foram a manutenção da estabilidade hídrica e o aumento da conectividade na microbacia, por meio da identificação de zonas de maior fragilidade ambiental, considerando a hidrografia, a geomorfologia, a pedologia e a distribuição dos fragmentos florestais remanescentes. A pesquisa de campo foi realizada com auxílio de imagens de satélite e fotografias aéreas em uma microbacia com 4.629,47 ha no entorno do Parque Nacional do Iguaçu, Terceiro Planalto Paranaense. Foram efetuados diferentes diagnósticos dos aspectos bióticos e abióticos, resultando em uma simulação do uso adequado do solo e no aumento da conectividade com a formação de corredor ecológico. A aplicabilidade do método foi demonstrada com a simulação de zonas para conservação e recuperação, que representaram $34,4 \%$ da área da microbacia nas zonas de menor potencial de utilização agropecuária, em função da fragilidade de seus solos. Os resultados demonstraram que ganhos ambientais significativos podem ser obtidos com a aplicação da metodologia, proporcionando o aumento da conectividade entre os fragmentos remanescentes.
\end{abstract}

Palavras-chave: Fragmentação; ecologia de paisagens; conservação da biodiversidade.

\begin{abstract}
Methodology for planning fragmented landscapes aiming the creation of Ecological Corridors. The purpose of this study is to develop a planning methodology which makes analyses of the structure of a certain landscape possible, as well as its biotic and abiotic characteristics in order to elaborate an adequate land use planning. Moreover, the guidelines of this study were maintenance of hydric stability and increasing of connectivity in the watershed by identification of regions with great environmental fragility, considering hydrography, geomorphology, pedology, and remaining forest patches. In field survey, satellite image and aerial photographs were used. The watershed studied has 4,629.47 ha and is located near Iguaçu National Park on the third Paraná plateau. Several biotic and abiotic aspects were distinguished in order to simulate an adequate land use and to establish a biodiversity corridor. This method was validated by simulating conservation and recovery zones, which cover $34.4 \%$ of watershed area. Such zones represent low potential regarding crops and cattle raising due to their fragile soil. Results showed the applicability of the methodology used, reflecting environmental gains, providing the increasing of connectivity among remaining forest patches.

Keywords: Fragmentation; landscape ecology; biodiversity conservation.
\end{abstract}

\section{INTRODUÇÃO}

Considerando os limitados recursos disponíveis para aplicação na área ambiental, há necessidade de esforços para priorizar as ações de proteção à biodiversidade. Nesse sentido, para que o planejamento do 
uso do solo em paisagens fragmentadas se constitua numa importante estratégia de conservação, há que se obter primeiramente o conhecimento das condições originais do meio, diagnóstico de fundamental importância para a previsão de sua dinâmica. O planejamento deve primar pela adoção de técnicas que assegurem a conservação das áreas de maior fragilidade, a estabilidade e a manutenção das funcionalidades de cada ambiente, bem como o aumento da conectividade, visando minimizar os efeitos da fragmentação dos ecossistemas.

Citada como a maior ameaça para a biodiversidade do planeta (TABARELLI; GASCON, 2005), a fragmentação de habitats acarreta o isolamento das formações e populações remanescentes, alterações nos fluxos gênicos, intensificação das competições, alterações da estrutura e qualidade de habitats, extinções de espécies e perda de biodiversidade (CAMPOS; AGOSTINHO, 1997; METZGER, 1998; BIERREGAARD et al., 1992; PRIMACK; RODRIGUES, 2001). Conforme Forman (1995), "o desenho de paisagens e regiões sustentáveis é essencial para manter simultaneamente a integridade ecológica (incluindo a biodiversidade) e as necessidades humanas básicas por gerações".

No estado do Paraná, o processo de ocupação territorial desordenado resultou em significativas perdas de biodiversidade. Estima-se que, de um número aproximado de 7.000 espécies vegetais ocorrentes no estado, cerca de 70\% (5.000) têm hoje seus ambientes alterados a ponto de colocar em risco os processos de interação ecossistêmica. A Lista Vermelha de Plantas Ameaçadas de Extinção no Estado do Paraná relaciona 593 espécies consideradas em situação crítica (PARANÁ, 1995). Por sua vez, o estudo realizado para o Livro Vermelho da Fauna Ameaçada no Estado do Paraná (MIKICH; BÉRNILS, 2004) diagnosticou 344 espécies, das quais 163 espécies foram consideradas ameaçadas de extinção.

Conforme Metzger (1998), a compreensão da influência da conectividade e da complexidade do mosaico sobre as populações e comunidades fragmentadas é particularmente urgente onde o processo de fragmentação e degradação da cobertura original é intenso e ultrapassou o limiar de $30 \%$ de cobertura florestal, proposto por Andrén (1994). A partir da década de 1960, a cobertura florestal no Paraná atingiu níveis inferiores a 30\% de sua superfície, tornando fundamental a preocupação com o arranjo dos elementos na paisagem. Assim, o planejamento do uso do solo, considerando a distribuição espacial dos remanescentes florestais, tornou-se uma importante ferramenta para propostas que visam à minimização dos impactos causados pela fragmentação de habitats.

Conforme Soulé; Gilpin (1991) e Saunders; Hobbs (1991), os corredores ecológicos são estruturas lineares da paisagem que ligam pelo menos dois fragmentos que originalmente eram conectados. O aumento da conectividade, por meio dos corredores ecológicos, constitui uma estratégia para reverter o quadro de fragmentação e isolamento de populações. Vários autores recomendam a manutenção ou restauração de corredores como estratégias para a conservação da biodiversidade: "Manter corredores que promovam conexão entre os fragmentos" (FORMAN, 1995); "Proteger corredores que unam habitats naturais" (KREMEN; RAYMOND; LANCE, 1998);"Restaurar a conectividade" (MCINTYRE; HOBBS, 1999). Os corredores são reconhecidamente importantes para o controle de fluxos hídricos e biológicos na paisagem (FORMAN; GODRON, 1986).

A conectividade funcional considera a medida de quanto um organismo ou espécie usa as diferentes feições da paisagem (i.e., manchas de habitat, corredores e matriz), estando relacionada à probabilidade de um organismo cruzar a paisagem (TAYLOR et al; 1993, RIBEIRO et al., 2009). A restauração da conectividade estrutural possibilita a conexão entre habitats fragmentados, promovendo o movimento de organismos, auxiliando na preservação da biodiversidade de ecossistemas e nas funções das comunidades (SOULÉ; GILPIN, 1991; CAMPOS, 2003; MYERS; BAZELY, 2003). Já o aumento da conectividade funcional se refere especificamente à intensidade de movimentos inter-habitat dos organismos (MERRIAM, 1984; 1991), os quais poderão ser avaliados pelos fluxos de disseminação. Fatores como largura do corredor e características quanto à permeabilidade da matriz podem influenciar fluxos de forma diferenciada, dependendo das características das espécies. Portanto, quanto à avaliação da efetividade da implantação de corredores (conectividade funcional), somente pode ser aferida em trabalhos de ecologia populacional e fluxo gênico entre fragmentos, dentre outros métodos específicos que possam mensurar de acordo com a sensibilidade de cada espécie alvo. Poucos trabalhos abordaram a conectividade como um parâmetro funcional da paisagem, que depende de características das espécies e/ou grupos funcionais estudados (RIBEIRO, 2009). Contudo, estudos demonstram que espécies se movem com mais frequência entre os sistemas ligados por corredores que entre fragmentos desconectados (HADDAD, 1999). A importância de corredores para plantas vasculares ainda foi pouco estudada, mas a 
conectividade influencia indiretamente a abundância e distribuição de plantas com sementes, na medida em que interfere diretamente na locomoção dos agentes de disseminação (METZGER, 1998). Estudo publicado pela revista Science, coordenado por Damschen et al. (2006), demonstrou a funcionalidade dos corredores, os quais auxiliam na diversidade de plantas através do aumento da polinização e dispersão de sementes. Dessa forma, a partir de um incremento da conectividade estrutural, que considera as condições físicas, topográficas e espaciais dos elementos da paisagem, pode ser esperado que ocorra também um incremento dos fluxos biológicos (conectividade funcional), já que os fatores estruturais são determinantes para dificultar ou facilitar o trânsito de determinadas espécies pela paisagem.

Para Goodwin; Fahrig (2002), a influência da estrutura espacial do habitat parece muito mais importante do que a influência da estrutura espacial da matriz na conectividade da paisagem. Conforme Metzger (1998), componentes simples, como tipo de fragmento, número, área, forma e efeito de borda, podem ser correlacionados para uma melhor compreensão da diversidade. Nesse sentido, este estudo propõe a conservação dos remanescentes florestais como zonas-núcleo de biodiversidade, os quais, conectados por corredores, devem proporcionar incrementos nos fluxos genéticos entre populações de fauna e flora. Considera também que um planejamento adequado por microbacia deve prever "onde" implantar os corredores visando o máximo de ganho ambiental, sem, contudo, inviabilizar as propriedades privadas, sendo factíveis de implantação. Sob essa ótica, o zoneamento ambiental torna possível representar a espacialização das informações, sendo uma ferramenta de prevenção, controle e monitoramento dos impactos ambientais, de acordo com as especificidades do território (SILVA, 1997). Portanto, contemplar o zoneamento fundamentado no diagnóstico dos fatores bióticos e abióticos pode ser a alternativa técnica aplicável, tanto para a conservação da diversidade biológica como para o planejamento e implantação de sistemas produtivos menos impactantes.

Dentre algumas iniciativas que preveem a formação de corredores no Brasil, destacam-se os projetos do Ministério do Meio Ambiente para o Corredor Central da Amazônia e o Corredor Central da Mata Atlântica (MMA, 2007). Cabe destacar que, além da recuperação estrutural, é de fundamental importância a adoção de práticas que permitam a facilitação dos fluxos, aumentando a permeabilidade da matriz. A estratégia de formação de corredores ecológicos adotada pelo Projeto Paraná Biodiversidade - PRBIO (PARANÁ, 2001) previu nesse estudo a metodologia necessária para o planejamento de microbacias em corredores, planejamento macroestratégico, resultado a ser replicado para outras regiões. Além da formação de corredores, o PRBIO teve o objetivo de desenvolver e implementar modelo de gestão ambiental que promovesse atividades menos impactantes nas práticas agropecuárias, prevendo o aumento da permeabilidade da matriz. Nesse sentido, o projeto apoiou a implantação de módulos de sistemas agroecológicos, com o objetivo de facilitar os fluxos biológicos e o aumento da conectividade efetiva na matriz. Outras práticas similares estão sendo realizadas na região do Pontal do Paranapanema, onde são instaladas zonas-tampão agroflorestais no entorno dos principais fragmentos florestais, como fonte de lenha, madeira, frutos, grãos e forragem, aliviando assim a pressão exercida pelos proprietários locais sobre os principais remanescentes (CULLEN et al., 2001). Tais procedimentos criam ambientes menos impactantes, limítrofes aos fragmentos florestais remanescentes, à medida que podem diminuir o efeito de borda $\mathrm{e}$ impactos negativos da matriz.

Objetivou-se com este estudo a elaboração de uma metodologia para o planejamento do uso adequado da paisagem, sob o aspecto estrutural, considerando-se fatores abióticos e bióticos do meio e da estrutura da paisagem, com vistas a aumentar a conectividade e a formação de corredores ecológicos, bem como a estabilidade hídrica e ambiental da microbacia. Os objetivos específicos são caracterizar os principais fatores bióticos e abióticos na área de estudo, analisar como esses fatores interferem na dinâmica do ambiente da microbacia, identificar áreas de fragilidade ambiental, definir áreas a recuperar visando o aumento da conectividade entre fragmentos florestais e indicar ações para incrementar a proteção dos remanescentes prioritários. Os procedimentos adotados resultaram numa metodologia de planejamento de incremento da conectividade estrutural por microbacia, apresentada na conclusão deste trabalho.

\section{MATERIAL E MÉTODOS}

\section{Área de estudo}

A área de estudo abrange 4.643,83 ha, nos municípios de Santa Tereza do Oeste, Céu Azul e São Pedro do Iguaçu, e integra o Corredor Iguaçu-Paraná do Projeto Paraná Biodiversidade (Figura 1). Está 
inserida na bacia do rio São Francisco Falso, Braço Norte, contribuinte do reservatório de Itaipu (rio Paraná), cujas nascentes situam-se próximas à BR-277, na divisa com o Parque Nacional do Iguaçu. As altitudes variam de 740 a $520 \mathrm{~m}$, representando um desnível de $220 \mathrm{~m}$. A microbacia foi definida em função da localização e da conectividade entre o Parque Nacional do Iguaçu, o Parque Estadual da Cabeça do Cachorro e a Poligonal Envolvente do Lago de Itaipu Binacional. Considerando o nível de detalhamento previsto, foi delimitado o segmento superior dessa microbacia, onde é possível evidenciar as diversas características geomorfológicas, pedológicas e vegetacionais que ocorrem predominantemente na região.

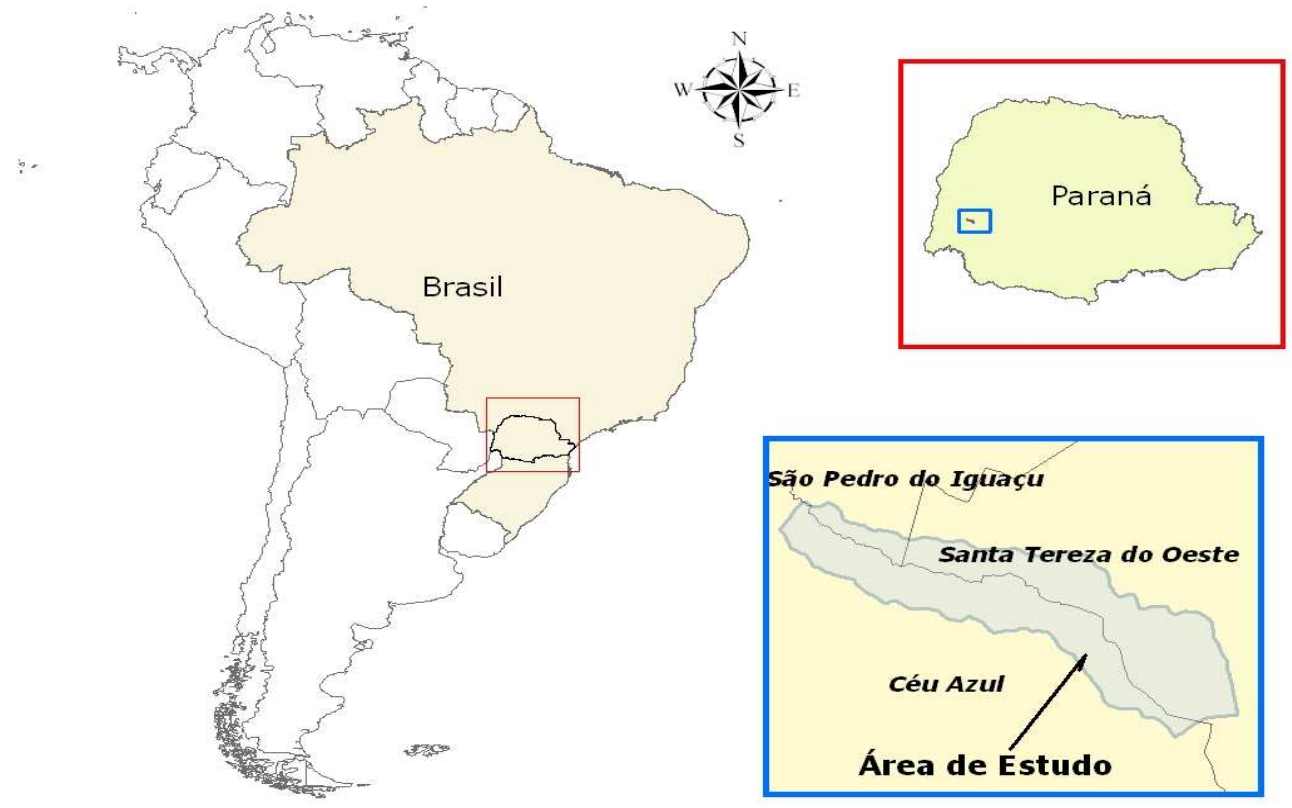

Figura 1. Localização da área de estudo.

Figure 1. Location of the study site.

\section{Materiais}

A documentação cartográfica utilizada para o presente trabalho consistiu de fotografias aéreas verticais métricas, de 1980, na escala 1:25.000, e também de imagens orbitais do satélite "SPOT" com resolução de $5 \mathrm{~m}$ do ano de 2005.

\section{Procedimentos metodológicos}

As imagens de satélite (SPOT5-2005) e as fotografias aéreas de 1980 (escala 1:25.000) serviram de base para o mapeamento da cobertura vegetal natural e do uso do solo, realizado com a classificação visual das imagens. Com esses primeiros resultados, foram delimitadas as áreas de agricultura, pecuária, reflorestamento, urbanização e de vegetação nativa. As edições dos mapas e imagens foram executadas com uso do programa ARCGIS 9. A obtenção dos dados estatísticos e de métricas da paisagem foi realizada por meio do programa Fragstats 3.3 (MCGARIGAL; MARKS, 1995).

Para o mapeamento de solos, foram determinados os pontos amostrais nas fotografias aéreas, considerando-se as características de relevo, comprimento de rampa e posição na paisagem, para posteriormente serem realizadas as topossequências, num total de 23 , para a conclusão do mapeamento semidetalhado.

As informações desses dois mapas-base (classificação de solos e cobertura vegetal natural e uso do solo) foram analisadas de forma interdependente, visando determinar zonas de fragilidade ambiental para a área estudada. A manutenção da estabilidade ambiental, considerando primeiramente a questão hídrica, foi preponderante e resultou no mapeamento das áreas de fragilidade quanto aos aspectos abióticos, em ambientes de encosta e em ambientes fluviais. Quanto aos aspectos da rede de drenagem, foram mapeadas as áreas de cabeceiras de drenagem e de solos hidromórficos (Organossolos, Gleissolos). 
Foram definidas áreas que precisam ser recuperadas, objetivando a garantia da funcionalidade dos ambientes, primeiramente com base nas áreas situadas em zonas de alta fragilidade quanto aos aspectos abióticos, sem cobertura florestal: zonas de encosta, de influência aluvial, de solos rasos e/ou com pedregosidade. Foi também considerado que o fator isolamento e efeito de borda nos fragmentos os remete a uma condição de alta fragilidade. Assim, foram estabelecidas zonas de recuperação no entorno dos fragmentos prioritários, com largura de $35 \mathrm{~m}$, para o aumento da área-núcleo e melhoria na qualidade dos mesmos (CULLEN et al., 2001).

Com base nas informações das áreas de fragilidade ambiental, das áreas que precisam ser recuperadas e de áreas prioritárias para conservação, obteve-se o mapeamento final, com uma proposta de zoneamento com áreas a serem conservadas, constituindo um corredor de biodiversidade, e aquelas passíveis de utilização.

O índice de conectividade (porcentagem de fragmentos que estariam conectados com uma distância de dispersão de $100 \mathrm{~m}$ de raio) foi usado como comparativo entre a situação atual da microbacia e um cenário idealizado simulado no presente estudo. Por fim, foram realizadas simulações visando a comparação do modelo proposto com as exigências de conservação da legislação atual, obtendo-se uma avaliação da viabilidade de sua implementação em campo.

\section{RESULTADOS}

Conforme a metodologia proposta, as primeiras análises da área de estudo foram relativas aos aspectos abióticos do meio, seguindo-se das informações da cobertura vegetal e da estrutura da paisagem, que, de forma complementar, possibilitaram a definição das áreas para implantação dos corredores. Os primeiros resultados, relativos ao diagnóstico dos tipos de solo e das características hidromorfológicas da microbacia, foram essenciais para a delimitação das áreas de maior vulnerabilidade, com ênfase especial à erosão potencial, devido à espessura do solo, ao grau de declividade, à forma de rampa e à posição na paisagem. No Paraná, a erosão laminar, em sulcos e em voçorocas ocorre em larga escala, podendo acarretar em perdas de 100 a $200 \mathrm{t}$ de solo por ha/ano, e em extremos até $700 \mathrm{t}$ ha/ano (DERPSCH et al., 1991).

\section{Análise dos fatores abióticos}

No processo de evolução da paisagem, a área da microbacia do rio São Francisco Falso encontrase regida pelo nível de base do rio Paraná. O modelamento está condicionado por lineamentos geológicos, os quais propiciam a dissecação do relevo. $\mathrm{Na}$ área do estudo, foram identificadas duas províncias geomórficas distintas: relevos convexados, na porção superior, e patamarizados, a partir do segundo terço para jusante.

Com a identificação dos cursos d'água e das cabeceiras de drenagem nas fotografias aéreas e imagens de satélites, foi elaborado o mapa hidrográfico da área (Figura 2). Pode-se observar que a rede de drenagem na porção da microbacia com relevos convexados é menos densa que nos patamarizados, em consonância com IAPAR (1999), que relaciona os atributos dos solos com a densidade de drenagem: baixas densidades com maiores profundidades de solos são predominantes nas pedoformas convexas, e altas densidades de drenagem com menores profundidades de solo são predominantes nas côncavas.

O mapeamento semidetalhado (Figura 3) possibilitou a avaliação das vulnerabilidades pedológicas, resultado a ser utilizado quando da avaliação e cruzamentos com os outros fatores do meio. Os solos da microbacia (Tabela 1) foram diferenciados e classificados conforme o modelamento da paisagem (Tabela 2).

É importante destacar que os solos de alta fragilidade em ambientes fluviais (Organossolos e Gleissolos Melânicos) representam 4,27\% da área de estudo. Já os Neossolos Litólicos e Neossolos Regolíticos representam 13,87\%. Essas áreas de solos, altamente vulneráveis, representam $18,14 \%$ da área total estudada e devem compor zonas destinadas à conservação ambiental, podendo assim integrar ou realizar conexões visando à formação do corredor de biodiversidade.

\section{Análise da cobertura vegetal natural e uso do solo}

Na bacia do rio São Francisco Falso, entremeado às atividades agropastoris, observa-se um mosaico de diferentes fisionomias da vegetação nativa, na forma de fragmentos remanescentes da floresta original 
e de fases sucessionais da vegetação secundária (Figura 4). Na área de estudo, que compreende 4.629,95 ha, foram identificadas 125 manchas, divididas de acordo com o tipo de uso do solo (Tabela 3).

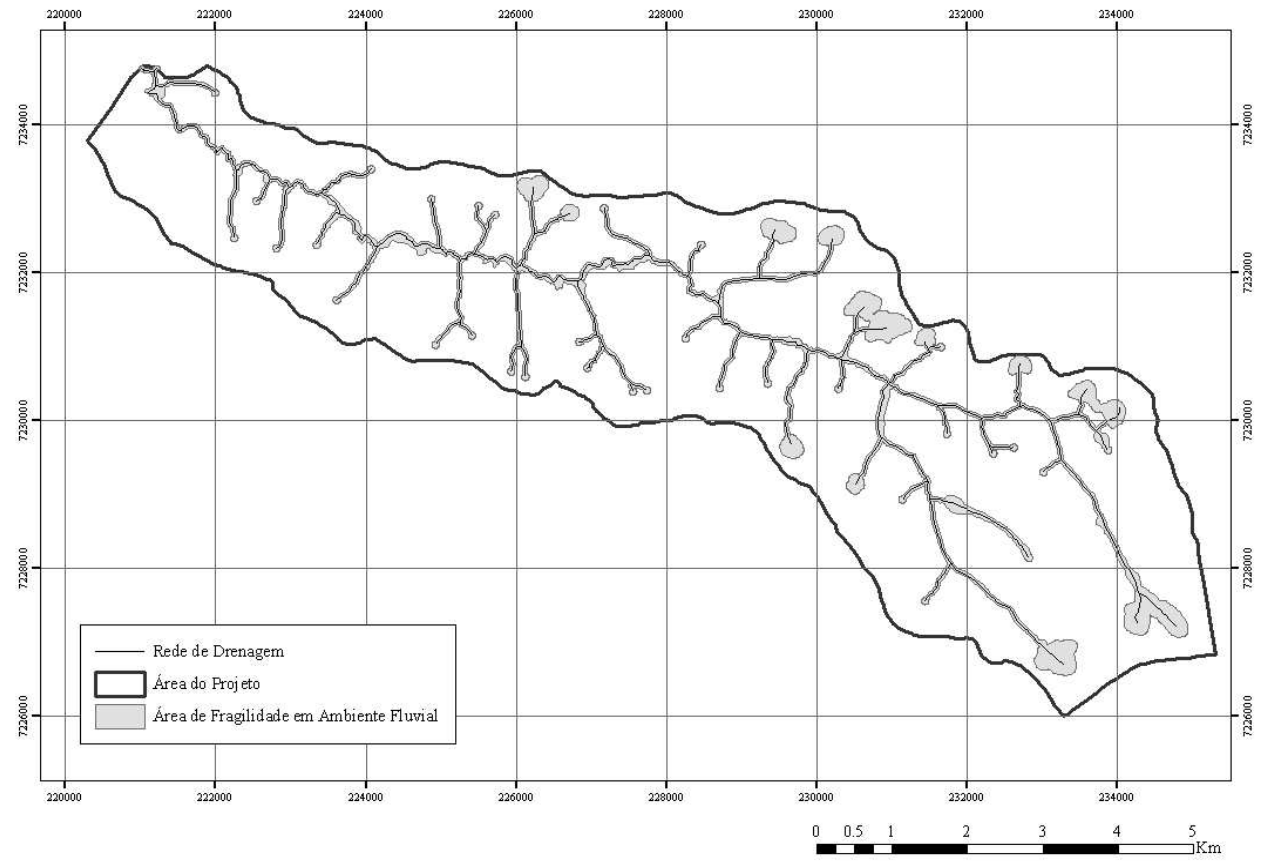

Figura 2. Hidrografia da área de estudo.

Figure 2. Hydrography of the study site.

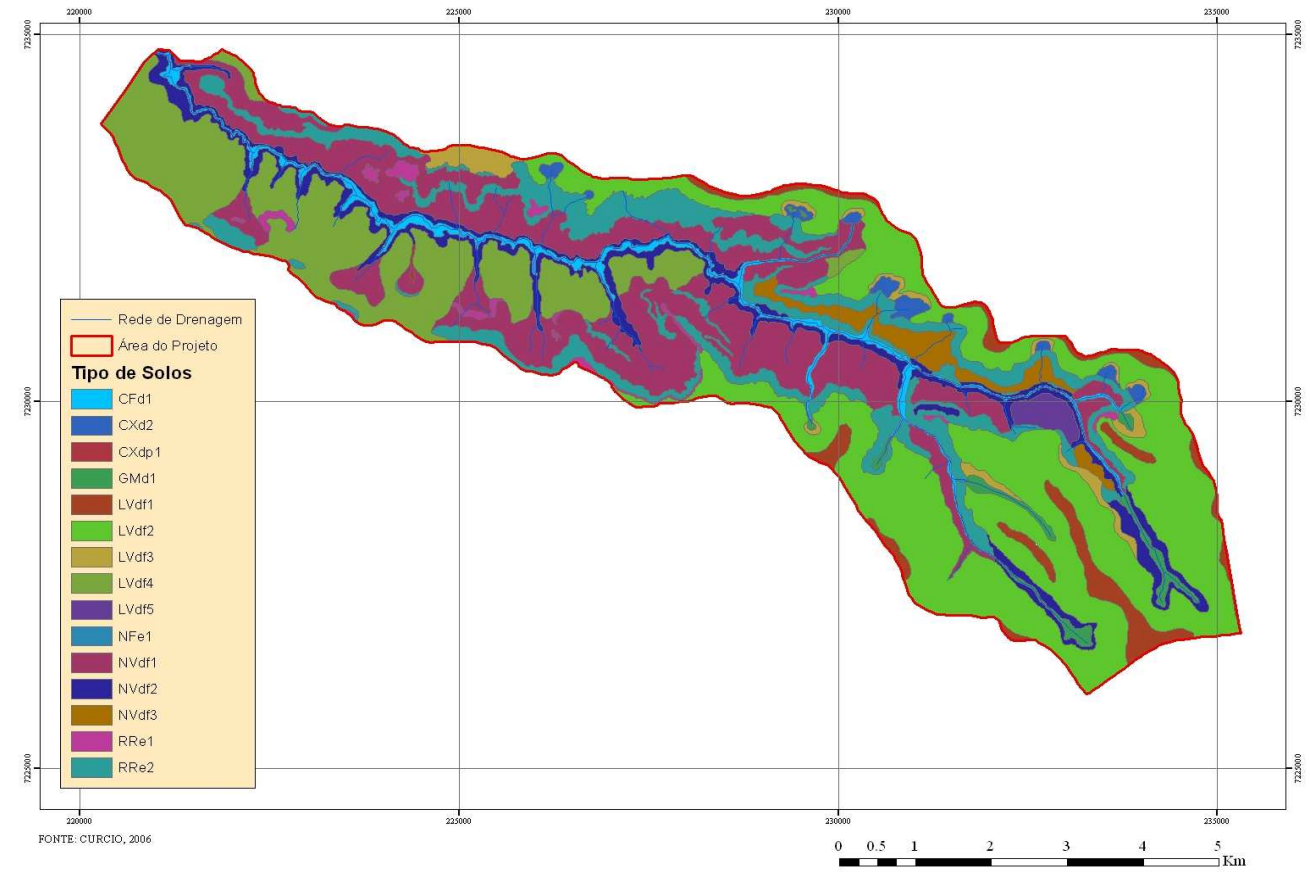

Figura 3. Mapa semidetalhado dos solos da porção superior da Microbacia do Rio São Francisco Falso (Braço Norte).

Figure 3. Semi-detailed soil map from upland São Francisco Falso river (North Branch watershed). 
Tabela 1. Distribuição de classes de solo na microbacia (\%).

Table 1. Soil distribution in the watershed (\%).

\begin{tabular}{|c|c|c|c|}
\hline & Tipo de solo & Área (ha) & $\%$ \\
\hline LVdf2 & $\begin{array}{l}\text { LATOSSOLO VERMELHO Distroférrico típico A proeminente e } \\
\text { moderado epieutrófico textura argilosa relevo suave ondulado. } \\
\text { NITOSSOLO VERMELHO Distroférrico típico A moderado e }\end{array}$ & 1347,48 & 29,10 \\
\hline NVdf1 & proeminente textura argilosa relevo ondulado. & 974,80 & 21,00 \\
\hline LVdf4 & $\begin{array}{l}\text { LATOSSOLO VERMELHO Distroférrico nitossólico A proeminente e } \\
\text { moderado epieutrófico textura argilosa relevo suave ondulado. } \\
\text { Associação NEOSSOLO REGOLÍTICO + NEOSSOLO LITÓLICO }\end{array}$ & 702,80 & 15,10 \\
\hline RRe2 & $\begin{array}{l}\text { ambos Eutróficos típicos A moderado/fase erodida textura argilosa e } \\
\text { média cascalhento pedregoso relevo forte ondulado e montanhoso } \\
\text { substrato rochas eruptivas + Afloramento de rochas eruptivas. } \\
\text { Associação NITOSSOLO VERMELHO Eutroférrico + CAMBISSOLO } \\
\text { HÁPLICO Eutrófico ambos típicos A moderado textura argilosa relevo }\end{array}$ & 590,79 & 12,76 \\
\hline NVdf2 & $\begin{array}{l}\text { ondulado. } \\
\text { LATOSSOLO VERMELHO Distroférrico típico A proeminente e }\end{array}$ & 315,31 & 6,81 \\
\hline LVdf1 & $\begin{array}{l}\text { moderado epieutrófico textura argilosa relevo plano. } \\
\text { Associação CAMBISSOLO FLÚVICO fase terraço + NEOSSOLO }\end{array}$ & 175,96 & 3,80 \\
\hline CFd1 & $\begin{array}{l}\text { FLÚVICO ambos Eutróficos típicos A moderado textura argilosa relevo } \\
\text { plano e suave ondulado. } \\
\text { Associação NITOSSOLO VERMELHO Distroférrico + CAMBISSOLO }\end{array}$ & 140,54 & 3,04 \\
\hline NVdf3 & $\begin{array}{l}\text { HÁPLICO Eutrófico ambos típicos A moderado textura argilosa relevo } \\
\text { ondulado. } \\
\text { LATOSSOLO VERMELHO Distroférrico tínico A proeminente e }\end{array}$ & 102,48 & 2,21 \\
\hline LVdf3 & $\begin{array}{l}\text { LATOSSOLO VERMELHO Distroférrico típico A proeminente e } \\
\text { moderado epieutrófico textura argilosa relevo ondulado. } \\
\text { GLEISSOLO MELÂNICO Distrófico típico húmico e hístico fase } \\
\text { soterrada textura argilosa relevo plano e suave ondulado, }\end{array}$ & 89,96 & 1,94 \\
\hline GMd1 & $\begin{array}{l}\text { ORGANOSSOLO. } \\
\text { Associação NEOSSOLO REGOLÍTICO Eutrófico típico A moderado e fase } \\
\text { erodida textura argilosa e média cascalhento pedregoso relevo suave ondulado }\end{array}$ & 55,25 & 1,19 \\
\hline RRe1 & $\begin{array}{l}\text { e ondulado substrato rochas eruptivas + Afloramento de rochas eruptivas. } \\
\text { CAMBISSOLO HÁPLICO Eutrófico nano e léptico A moderado textura }\end{array}$ & 51,31 & 1,11 \\
\hline $\mathrm{CXd} 2$ & $\begin{array}{l}\text { argilosa relevo ondulado substrato rochas eruptivas. } \\
\text { LATOSSOLO VERMELHO Distroférrico nitossólico A proeminente e }\end{array}$ & 44,00 & 0,95 \\
\hline LVdf5 & $\begin{array}{l}\text { moderado epieutrófico textura argilosa relevo ondulado. } \\
\text { CAMBISSOLO HÁPLICO Distrófico petroplíntico A moderado textura }\end{array}$ & 35,06 & 0,76 \\
\hline CXdp1 & $\begin{array}{l}\text { argilosa relevo ondulado substrato rochas eruptivas. } \\
\text { NEOSSOLO FLÚVICO Eutrófico nano A moderado textura argilosa }\end{array}$ & 2,11 & 0,05 \\
\hline $\mathrm{NFe} 1$ & pedregoso relevo ondulado. & 2,10 & 0,05 \\
\hline \multicolumn{2}{|c|}{ TOTAL } & 4629,95 & 100 \\
\hline
\end{tabular}

Tabela 2. Classificação dos solos conforme SBCS (EMBRAPA, 1999).

Table 2. Soil classification according to SBCS (EMBRAPA, 1999).

\begin{tabular}{lcr}
\hline Paisagem & Classificação & \multicolumn{1}{c}{ Área } \\
\hline Encosta & Latossolo Vermelho & $2.351,26$ \\
& Nitossolo Vermelho & $1.392,59$ \\
& Cambissolo Háplico & 46,11 \\
& Neossolo Litólico+ Neossolo Regolítico & 642,10 \\
Planície & Neossolo Flúvico + Cambissolo Flúvico & 142,64 \\
& Gleissolo Melânico + Organossolo & 55,25 \\
\hline Total & & $4.629,95$ \\
\hline
\end{tabular}

A vegetação nativa compreende 19,37\%, distribuídos nos 57 fragmentos remanescentes. Observa-se o predomínio da agricultura, com $71 \%$ da área (matriz), enquanto a pecuária representa $9,11 \%$, dispostos em áreas de maior declive que as destinadas à agricultura intensiva. Nos reflorestamentos, que representam 0,33\%, predominam espécies do gênero Eucalyptus. 
Tabela 3. Cobertura vegetal natural e uso do solo na área de estudo.

Table 3. Natural plant cover and land use in the study site.

\begin{tabular}{lccc}
\hline Uso atual & Área & \% & Manchas \\
\hline Vegetação nativa & 900,13 & 19,37 & 57 \\
Agricultura & 3299,57 & 71,05 & 14 \\
Pecuária & 423,47 & 9,11 & 43 \\
Reflorestamento & 15,38 & 0,33 & 10 \\
Área urbana & 5,26 & 0,11 & 1 \\
\hline Total & 4643,81 & 100 & 125 \\
\hline
\end{tabular}

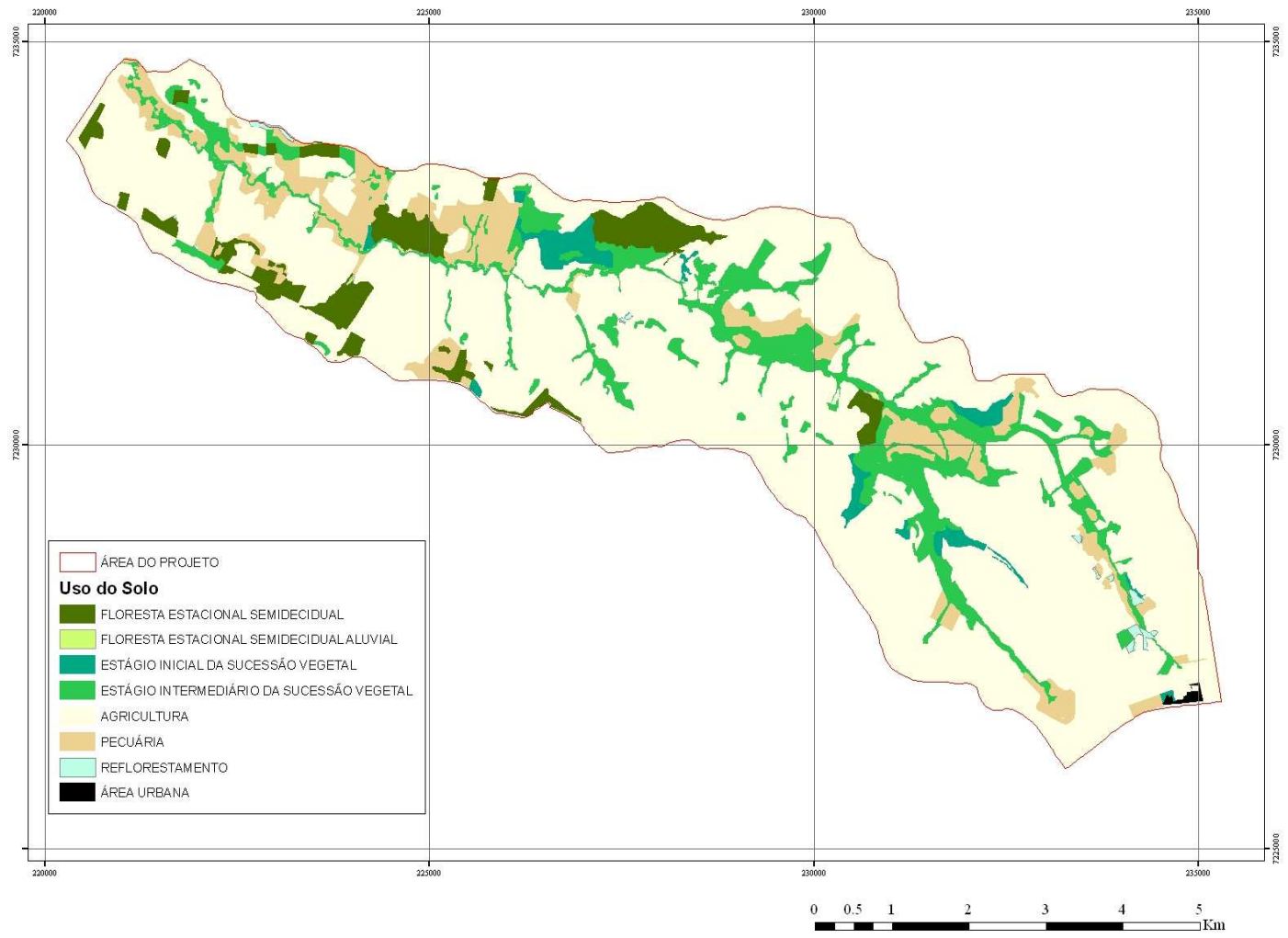

Figura 4. Cobertura vegetal e do uso do solo da área de estudo (Fonte: IAP/2006).

Figure 4. Vegetation cover and soil use in the study area (Source: IAP/2006).

Utilizando-se dos conceitos e métricas da ecologia da paisagem, foi observado que, para a área total de estudo, 19,37\% correspondem às áreas com cobertura florestal nativa, disposta em 57 fragmentos em diferentes estágios sucessionais da Floresta Estacional Semidecidual. Os ambientes florestais encontram-se fortemente alterados, mesmo os remanescentes da vegetação primária. O tamanho do menor fragmento é de 0,065 ha, e do maior, 684,28 ha, que corresponde a 76\% da cobertura florestal total. A área média dos fragmentos é de 15,79 ha. Em cada 100 ha, a densidade média de fragmentos (número de fragmentos em 100 ha) é de 6,33 , e a distância média de um fragmento ao seu vizinho mais próximo é de $78 \mathrm{~m}$ (Tabela 4).

\section{Definição das zonas de fragilidade quanto aos aspectos abióticos}

Nos relevos convexados, situados na porção superior da bacia, foram identificadas zonas de alta fragilidade ambiental nas porções inferiores das rampas longas, próximas aos cursos d'água, onde ocorrem solos hidromórficos (Organossolos, Gleissolos e Neossolos), altamente vulneráveis e que foram submetidos a soterramentos devido aos processos erosivos, originados nas porções superiores do relevo. Nas paisagens 
patamarizadas, que predominam a partir do segundo terço da área de estudo, as áreas de maior fragilidade foram identificadas nas encostas, nas porções de maior declividade, onde estão situados os solos rasos (Neossolos litólicos e Neossolos regolíticos), altamente erodíveis e que também, em função da alta CTC, necessitam de cobertura vegetal para evitar a perda de íons do sistema. Portanto, por meio do mapeamento dos solos, foi possível a identificação dessas áreas de maior fragilidade relativa aos aspectos do meio abiótico, que foram classificadas como de fragilidade relativa aos ambientes de encosta, com 642,10 ha, e fluviais, com 498,67 ha, cujo mapeamento final (Figura 5) totalizou 1128,40 ha. Nesses ambientes, a conservação é fator essencial para a estabilidade e equilíbrio da bacia.

Tabela 4. Resumo de parâmetros de cobertura florestal da área de estudo.

Table 4. Brief forest covers parameter of the study site.

\begin{tabular}{lc}
\hline Parâmetro & Valor \\
\hline Área com cobertura florestal & 900,13 ha \\
Número de fragmentos com cobertura florestal & 57 \\
Tamanho dos fragmentos & - \\
Mínimo & 0,065 ha \\
Máximo & $684,28 \mathrm{ha}$ \\
Médio & 15,79 ha \\
Densidade dos fragmentos florestais - número de fragmentos em 100 ha & 6,33 \\
Distância média ao vizinho mais próximo & $77,99 \mathrm{~m}$ \\
Conectividade & $2,25 \%$ \\
\hline
\end{tabular}

\section{Definição das áreas prioritárias para conservação considerando os aspectos bióticos e de estrutura da paisagem}

A área de estudo possui somente 19,37\% de cobertura florestal dispostos em fragmentos pouco conectados. Conforme Metzger (1998), onde o processo de fragmentação foi intenso e a cobertura florestal está abaixo do limiar de 30\%, faz-se necessário a compreensão da estrutura da paisagem visando ao restabelecimento da conectividade. Isso indica que todos os remanescentes têm relevância e devem ser conservados nessa microbacia, independentemente dos estágios sucessionais em que se encontram. Por meio do cruzamento das informações de disposição espacial e tamanho dos fragmentos, foi possível a elaboração do mapa de áreas prioritárias para conservação (Figura 6).

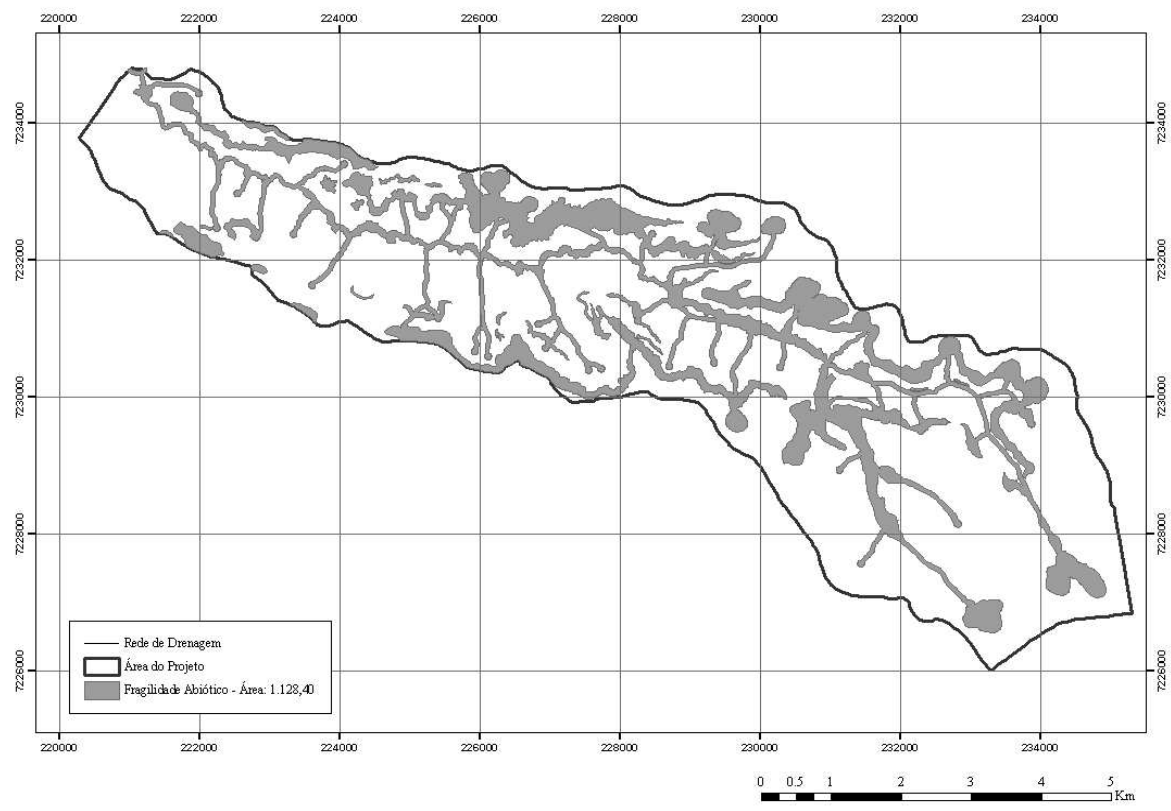

Figura 5. Áreas de fragilidade ambiental relativa aos aspectos abióticos.

Figure 5. Regions of environmental fragility regarding to abiotic compounds. 


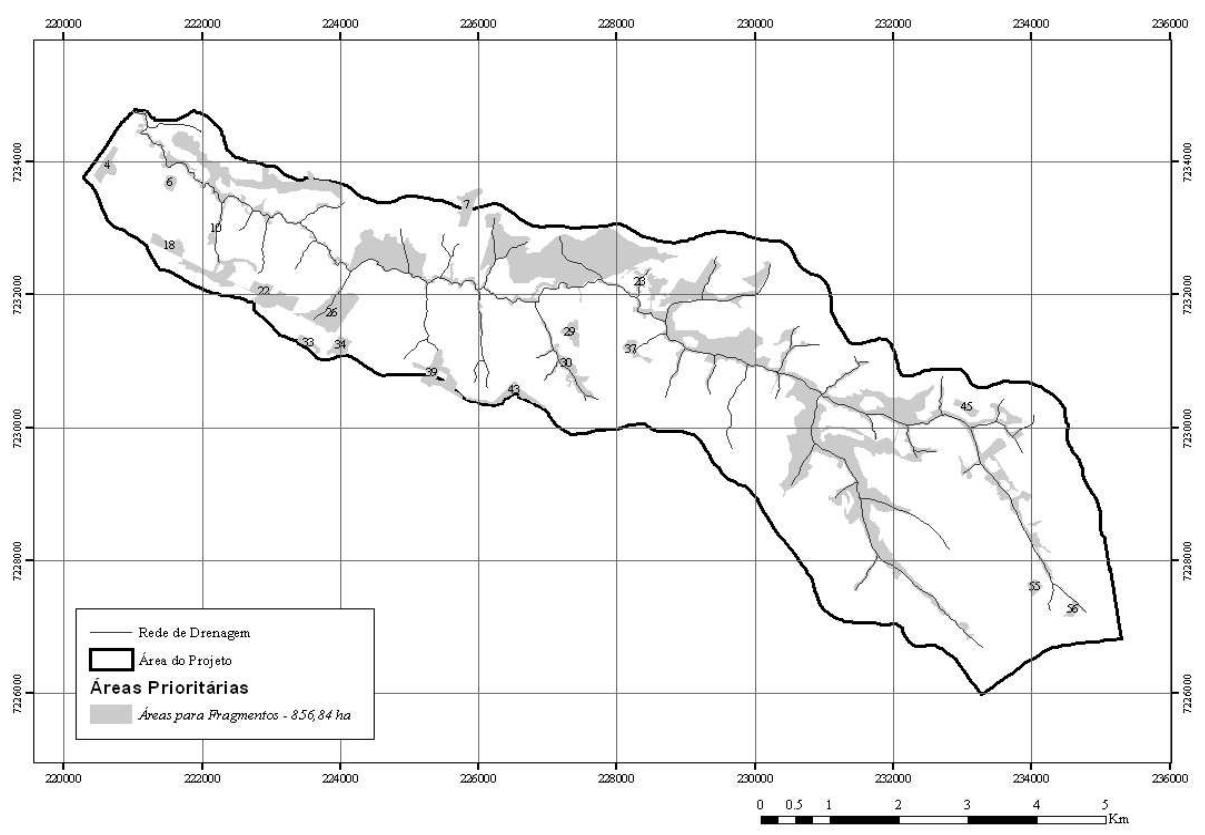

Figura 6. Áreas prioritárias para conservação considerando a vegetação existente e a estrutura da paisagem.

Figure 6. Priority region for conservation regarding to vegetation and landscape.

\section{Áreas prioritárias para restauração de ambientes}

Conforme apontam Metzger (2000) e Reis et al. (2003), incorporar os conceitos de fragmentação, permeabilidade da matriz, conectividade da paisagem, corredores biológicos, fluxo gênico e de organismos faz avançar a visão de restauração, ampliando os horizontes das ações em áreas degradadas. Para definir áreas a serem recuperadas na microbacia, foram utilizadas as seguintes premissas: aumento da cobertura florestal, proteção de áreas de fragilidade quanto às características abióticas do meio, aumento da conectividade entre os fragmentos florestais e proteção dos fragmentos selecionados como prioritários.

A identificação das áreas de fragilidade ambiental quanto aos aspectos fluviais e de encostas indicou a necessidade de recuperação de 601,48 ha, que representam 12,99\% da área de estudo (Tabela 5). A recuperação nessas áreas tem como objetivos principais a manutenção da estabilidade do ambiente e de suas funcionalidades, além dos aspectos legais.

Tabela 5. Localização e áreas das zonas de recuperação.

Table 5. Location and extent of recovery zones.

\begin{tabular}{|c|c|c|c|}
\hline Zonas & Localização & Área a recuperar & $\%$ \\
\hline Fragilidade & Ambientes fluviais e em encostas & 601,48 & 12,99 \\
\hline Entorno & $\begin{array}{l}\text { Expansão do entorno fragmentos } \\
\text { prioritários }\end{array}$ & 134,34 & 2,90 \\
\hline Área total a recuperar & - & 735,82 & 15,89 \\
\hline Área total de estudo & - & $4.629,95$ & 100,00 \\
\hline
\end{tabular}

\section{DISCUSSÃO}

O fato de os ambientes fluviais estarem inseridos na proposta estudada resultou em aumento considerável da conectividade, especialmente nos ambientes ripários, formando corredores de biodiversidade conectados pelas áreas ripárias. 
Nos ambientes de encosta, cuja conservação visa principalmente garantir a estabilidade quanto à erosão em solos rasos, em feições de maiores declives, foi observado que a restauração também contribuiria para o aumento da conectividade. Assim, as espécies não características dos ambientes ciliares também teriam possibilidade de conservação nas encostas, fato que acarretaria uma interligação mais heterogênea do que a esperada somente com conexões naqueles ambientes ciliares.

Considerando que as bordas dos fragmentos são extremamente suscetíveis às agressões exteriores, que podem ser provocadas pela ação do gado, pelo fogo e por práticas agrícolas e florestais (POGGIANI; OLIVEIRA, 1998), a implantação de reflorestamento, formando faixa protetora no entorno imediato dos fragmentos mais importantes, poderia contribuir para o aumento da proteção dos efeitos da matriz nos fragmentos e nas áreas-núcleo. Essa estratégia foi proposta no estudo, por meio de uma simulação, criando-se um buffer de $35 \mathrm{~m}$ no entorno de cada fragmento selecionado como prioritário. Essas zonas de amortecimento teriam como função a proteção desses remanescentes, que são altamente vulneráveis em função de sua condição de isolamento. Assim, poderiam ser reduzidos os efeitos negativos resultantes do contato dos fragmentos com a matriz, como invasão de espécies exóticas, fogo, efeitos do aumento da luminosidade e da temperatura e diminuição da umidade (efeitos de borda). Essa simulação resultou em uma área de 134,34 ha a serem recuperados no entorno dos 18 maiores remanescentes (Tabela 6). Após essa simulação, foi elaborado o mapeamento das áreas a serem restauradas, com base nos resultados das áreas de fragilidade ambiental quanto aos aspectos abióticos, ecologia da paisagem e entornos dos fragmentos prioritários (Figura 7).

Tabela 6. Características de área e porcentagens das diferentes zonas.

Table 6. Characteristics and relative extension of the different zones.

\begin{tabular}{|c|c|c|c|c|c|c|}
\hline Zonas & Localização & Área & $\%$ & $\begin{array}{c}\text { Área } \\
\text { Florestada }\end{array}$ & $\begin{array}{c}\text { Área a } \\
\text { Recuperar }\end{array}$ & $\%$ \\
\hline Fragilidade & Ambiente fluvial & 534,54 & 11,55 & 240,88 & 294,34 & \\
\hline Fragilidade & Encosta & 645,53 & 13,94 & 342,10 & 303,43 & \\
\hline Fragilidade total & Fluvial + Encosta & $1.128,40$ & 24,37 & 526,92 & 601,48 & 12,99 \\
\hline $\begin{array}{l}\text { Prioritária para } \\
\text { conservação }\end{array}$ & Conservação & 856,84 & 18,50 & 856,84 & & \\
\hline $\begin{array}{l}\text { Expansão no entorno dos } \\
\text { fragmentos prioritários }\end{array}$ & Recuperação & 134,34 & & & 134,34 & 2,90 \\
\hline Total a recuperar & & & & & 735,82 & 15,89 \\
\hline Total a conservar & & $1.592,66$ & 34,40 & & & \\
\hline $\begin{array}{l}\text { Total passível de } \\
\text { utilização }\end{array}$ & Agropecuária & $3.036,81$ & 65,60 & & & \\
\hline Área total de estudo & - & $4.629,95$ & 100,00 & & & \\
\hline
\end{tabular}

Com todos os critérios mencionados, as áreas indicadas para recuperação totalizaram 735,82 ha, que representam $15,89 \%$ da área estudada (Tabela 6). A cobertura florestal passaria de 900,13 ha para 1.501,61 ha. Evidente que a expansão da cobertura florestal incorrerá, necessariamente, em manejos intensivos nos sistemas produtivos, que possam compensar a rentabilidade dos produtores, um dos fatores básicos para convencimento dessa mudança.

A Floresta Estacional Semidecidual possui uma variedade de espécies nativas potenciais, que podem ser utilizadas tanto com o objetivo de conservação (CARVALHO, 2003) como para produção de madeira ou para alimentação de gado confinado. A visão do uso de espécies nativas necessita ser ampliada e viabilizada por projetos que incentivem os produtores a utilizarem-nas como alternativa rentável e compatível com os objetivos de conservação.

Após as análises realizadas, obteve-se o mapa final contendo a proposta de zoneamento para formação de corredor, que resultou em 1.592,66 ha a serem destinados à conservação (Figura 8). Essas áreas deveriam ser integralmente compostas com vegetação nativa, representando $34,40 \%$ da área de estudo, ou seja, é necessário um incremento de 735,82 ha de cobertura florestal nos ambientes definidos como de recuperação (Tabela 6). O restante da área da microbacia, 3.036,81 ha, que correspondem a $65,60 \%$, seria potencialmente adequado à produção agrossilvopastoril, cujo manejo deveria atender recomendações específicas de conservação dos recursos naturais, com ênfase a solos e água. 


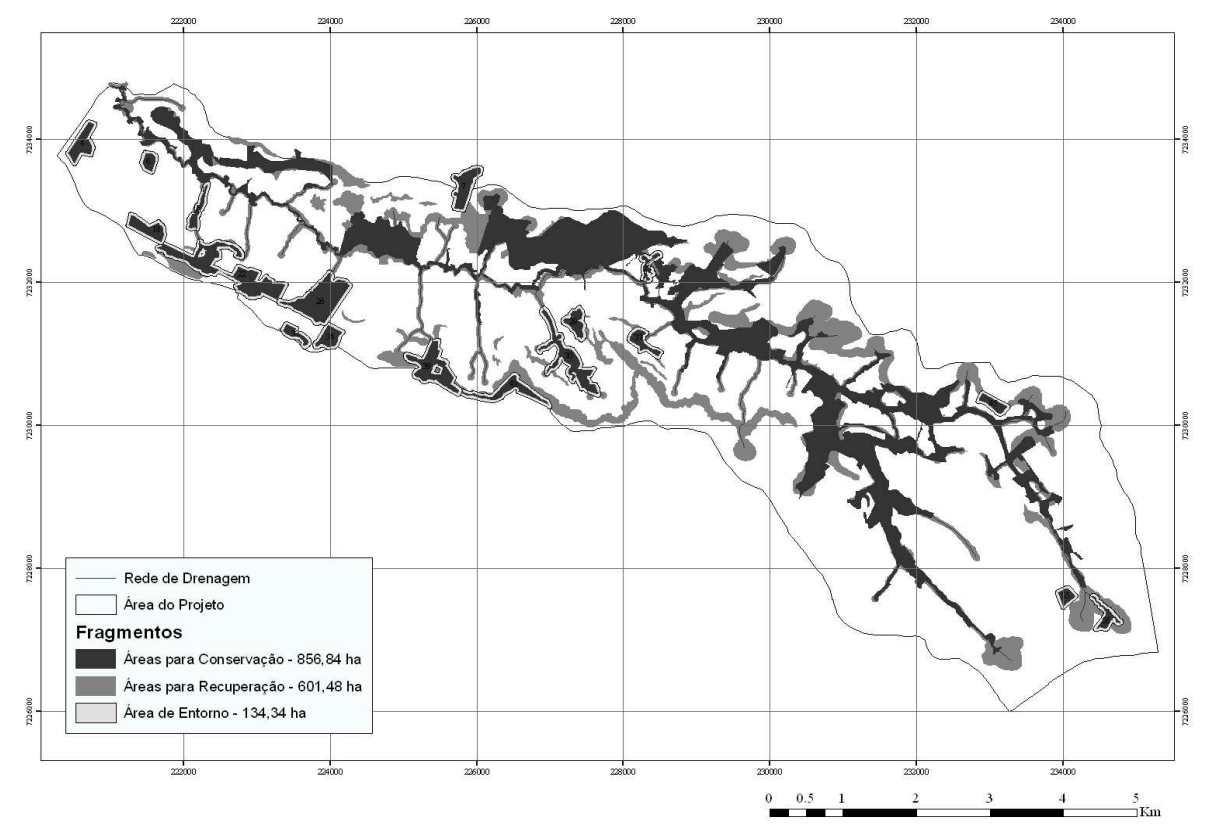

Figura 7. Zonas de recuperação.

Figure 7. Recovery zones.

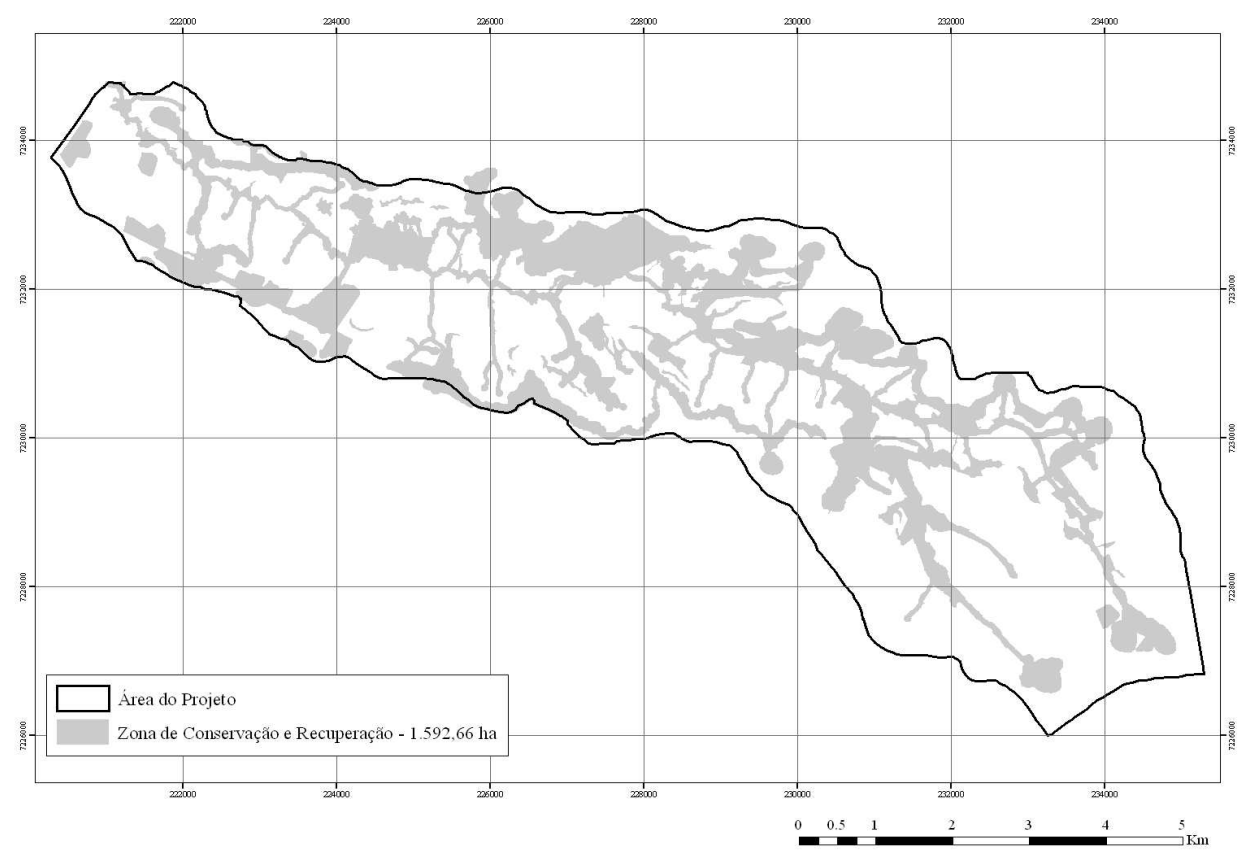

Figura 8. Áreas destinadas à conservação para formação de corredores de biodiversiade.

Figure 8. Regions to build biodiversity corridors.

Na situação atual, o maior fragmento possui 684,28 ha, e representa $76 \%$ da cobertura florestal existente $(900,13 \mathrm{ha})$. Na situação simulada, o maior fragmento teria $1.512,44$ ha, e representaria $97 \%$ da cobertura florestal total proposta para a área $(1.592,66$ ha). O tamanho médio dos fragmentos, que na 
situação atual é de 15,76 ha, seria de 129,54 ha na situação simulada. A conectividade, calculada para um raio de $100 \mathrm{~m}$, passaria de 2,25\%, na situação atual, para 13,63\% na situação simulada (Tabela 7).

Tabela 7. Métricas da situação atual e da situação simulada como ideal.

Table 7. Measurement of the real situation, and simulated situation as ideal one.

\begin{tabular}{|c|c|c|}
\hline Parâmetro & Situação atual & Situação simulada \\
\hline Área com cobertura florestal (ha) & 900,13 & $1.592,66$ \\
\hline Porcentual (\%) & 19,37 & 34,40 \\
\hline Número de fragmentos com cobertura florestal & 57 & 12 \\
\hline Tamanho dos fragmentos (ha) & - & - \\
\hline Mínimo & 0,065 & 2,37 \\
\hline Máximo & 684,28 & 1512,44 \\
\hline Médio & 15,79 & 129,54 \\
\hline Densidade dos fragmentos florestais ${ }^{(1)}$ & 6,33 & 0,77 \\
\hline Distância média ao vizinho mais próximo (m) & 77,99 & 81,40 \\
\hline Conectividade $^{(2)}$ & $2,25 \%$ & $13,63 \%$ \\
\hline
\end{tabular}

(1) Número de fragmentos em 100 ha. (2) Calculada por meio do programa Fragstat.

\section{CONCLUSÕES}

Os resultados deste estudo revelam que a conservação e a recuperação das zonas recomendadas, formando o corredor ecológico, poderiam acarretar melhorias significativas nas condições ambientais, fato evidenciado não somente pelo aumento na cobertura florestal, que de $19,37 \%$ passaria a $34,49 \%$, mas especialmente notado nos índices e métricas obtidos na simulação da implantação do zoneamento proposto. $\mathrm{O}$ número de fragmentos passaria de 57 para apenas 12, porém maiores e mais conectados. O tamanho médio dos fragmentos passaria de 15,79 ha a 129,54 ha, a conectividade de $2,25 \%$ seria de $13,63 \%$ e o maior fragmento (FEP) passaria de 684,28 ha a 1.512,44 ha de áreas estrategicamente conectadas ao longo dos ambientes fluviais. Além disso, o aumento das áreas dos fragmentos prioritários poderia acarretar a diminuição do efeito de borda e o aumento das áreas-núcleo nos fragmentos remanescentes.

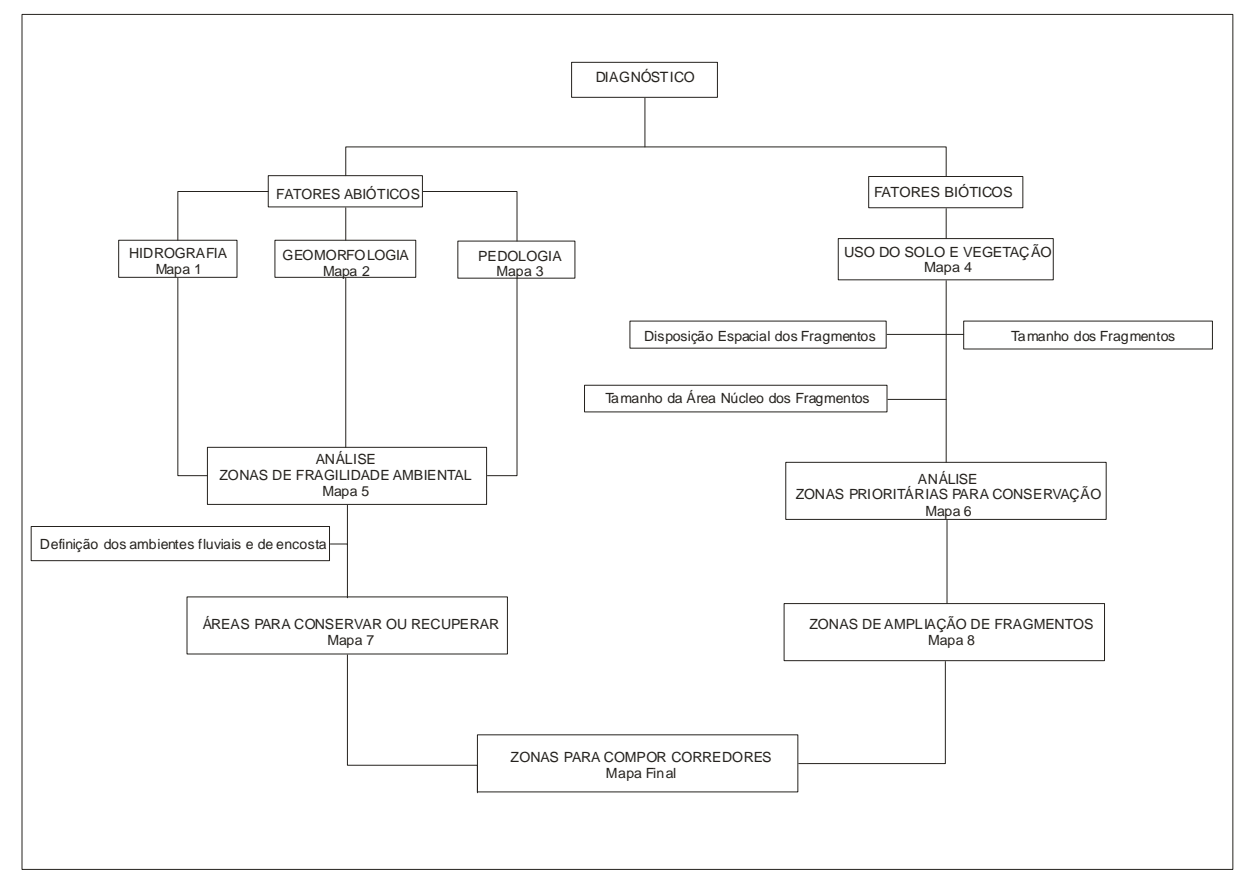

Figura 9. Fluxograma da metodologia.

Figure 9. Methodology flowchart. 
Conclui-se, assim, que o estudo resultou em uma metodologia para o planejamento de paisagens fragmentadas que, sendo aplicada em campo, poderá representar importantes ganhos ambientas (Figura 9). Essa estratégia contempla tanto a manutenção da estabilidade ambiental, por meio da conservação e restauração dos ambientes de maior fragilidade, como as vantagens de incremento de área florestada e da conectividade, no intuito de restaurar ao ambiente as funcionalidades dos corredores de biodiversidade, relativas ao incremento do fluxo gênico. Quanto a esse aspecto, que é amplamente ressaltado pela literatura, deve-se ressaltar que a efetividade do restabelecimento da conectividade funcional dependerá da sensibilidade das espécies e estudos que sejam capazes de mensurá-la.

Assim, esta metodologia de planejamento do uso do solo prevê o manejo da matriz e dos corredores da paisagem, os quais devem ser estabelecidos de forma a otimizar a conectividade e a possibilidade de trocas genéticas entre reservas naturais, zonas-núcleo de biodiversidade. $\mathrm{O}$ diferencial desta pesquisa se refere à localização das áreas para implantação das conexões para a formação dos corredores: em zonas de maior fragilidade ambiental, de baixo potencial agrícola (em função de suas características abióticas), relacionando preferencialmente os aspectos hídricos e de solos, essenciais para a estabilidade do ambiente da microbacia. Contudo, pesquisas mais aprofundadas poderiam contribuir para o aprimoramento do método proposto, a exemplo da análise do impacto social em cada propriedade, bem como análise da paisagem em unidades geomorfológicas distintas, o que permitiria aferir a viabilidade do método proposto para condições ambientais diferentes das observadas no presente estudo.

\section{REFERÊNCIAS}

BIERREGAARD, R. O.; LOVEJOY, T. E.; KAPOS, V.; SANTOS, A. A.; HUTCHINGS, R. W. The biological dynamics of tropical rain forest fragments. Bioscience, Wshington, DC, v. 42. n. 1, p. 859-866, 1992.

CAMPOS, J. B.; AGOSTINHO, A. A. Corredor de fluxo de biodiversidade do rio Paraná: uma proposta para a proteção ambiental de ecossistemas ameaçados. In: CONGRESSO BRASILEIRO DE UNIDADES DE CONSERVAÇÃO, 1, 1997, Curitiba. Anais... Curitiba: IAP/UNILIVRE/Rede Nacional Pró Unidade de Conservação, 1997. v. 2. p. 645-657.

CAMPOS, J. B. O papel dos corredores de biodiversidade. In: CONGRESSO MUNDIAL SOBRE AGRICULTURA CONSERVACIONISTA, 2., 2003, Foz do Iguaçu. Anais... Ponta Grossa: FEBRAPDP, 2003. p. 81-82.

CARVALHO, P. E. R. Espécies arbóreas brasileiras. Colombo: EMBRAPA Florestas, 2003. v. 1.

CREPANI, E.; MEDEIROS, J. S. de; HERNANDEZ, P.; FlORENZANO, T. G.; DUARTE, V.; BARBOSA, C. C. F. Sensoriamento remoto e geoprocessamento aplicado ao zoneamento ecológicoeconômico e ao ordenamento territorial. São José dos Campos: SAE/INPE, 2001.

CULLEN JR., L.; SCHMNIK, M.; VALLADARES-PADUA, C.; MORATO, I. Agroforesty Benefit zones: a tool for the conservation and management of Atlantic Forest Fragments, São Paulo, Brazil. Natural Areas Journal, Bend, v. 21, n. 4, p. 345-355, 2001.

DERPSCH, R.; ROTH, C. H.; SIDIRAS, N.; KÖPKE, U. Controle de erosão no Paraná, Brasil: sistemas de cobertura de solo, plantio direto e preparo conservacionista do solo. Eschborn: GTZ/IAPAR, 1991. $272 \mathrm{p}$.

EMPRESA BRASILEIRA DE PESQUISA AGROPECUÁRIA (EMBRAPA). Centro Nacional de Pesquisa de Solos. Sistema Brasileiro de Classificação de Solos. Rio de Janeiro, 1999. 412 p.

FORMAN, R. T. T. Land Mosaics: the ecology of landscapes and regions. Cambridge: Cambridge Uiniversity Press, 1995.

FORMAN, R. T. T.; GODRON, M. Landscape ecology. New York: J. Wiley \& Sons, 1986. 619 p.

GOODWIN, B. J.; FAHRIG, L. Effect of landscape structure on the movement behaviour of a specialized goldenrod beetle, Trirhabda borealis.Canadian Journal of Zoology, Ottawa, v.80, v.1, p. 25-34. 2002. 
HADDAD, N. M. Corridor and distance effects on interpatch movements: a landscape experiment with butterflies. Ecological Applications, Tempe, v. 9, 612- 622. 1999.

IAP - INSTITUTO AMBIENTAL DO PARANÁ. Interações dos meios bióticos e abióticos visando o reordenamento espacial da microbacia. Curitiba, 2006. 68 p. Apostila.

IPARDES - INSTITUTO PARANAENSE DE DESENVOLVIMENTO ECONÔMICO E SOCIAL. Uso e manejo de solos de baixa aptidão agrícola. Editado por Celso Castro Filho e Osmar Muzilli. Londrina, 1999. $270 \mathrm{p}$.

MCGARIGAL, K.; MARKS, B. J. FRAGSTATS: spatial pattern analysis program for quantifying landscape structure. Portland: U.S. Department of Agriculture, Forest Service, Pacific Northwest Research Station, 1995. (General Technical Report PNW 351).

MERRIAM, G. Connectivity: a fundamental ecological characteristic of landscape pattern. In: BRANDT, J.; AGGER, P. (Eds.). Methodology in Landscape: ecological research and planning. Roskilde: International Association for Landscape Ecology, 1984. p. 5-15.

MERRIAM, G. Corridors and connectivity: animal populations in heterogeneous environments. In: SAUDERS, D. A.; HOBBS, R. J. (Eds.). Nature Conservation 2: the hole of corridors. Chipping Norton: Surrey Beatty e Sons, 1991.p. 133-142.

METZGER, J. P. Landscape ecology approach in the preservation and rehabilitation of riparian forest areas in S.E. Brazil. In: CHAVÉZ, Salinas; MIDDLETON, John (Orgs.). Landscape Ecology as a Tool for Sustainable Development in Latin America. Logan: International Association for Landscape Ecology, 1998.

METZGER, J. P. Como restaurar a conectividade de paisagens fragmentadas. In: SIMPÓSIO DE RESTAURAÇÃO DE ECOSSISTEMAS DEGRADADOS COM ESPÉCIES NATIVAS. São Paulo: Edusp, 2000.

MIKICH, S. B.; BÉRNILS, R. S. Livro vermelho da fauna ameaçada no estado do Paraná. Curitiba: Instituto Ambiental do Paraná, 2004. 764 p.

MMA - BRASIL. Ministério do Meio Ambiente, 2007. Dísponível em: <HTTP://www.mma.gov.br>. Acesso em 23/07/2007.

MYERS, J.; BAZELY, D. Ecology and Control of Introduced Plants. Ecology, Biodiversity and Conservation, Cambridge, p. 35-49, 2003.

PARANÁ. Secretaria de Estado do Meio Ambiente. Lista vermelha de plantas ameaçados de extinção no Estado do Paraná. Curitiba: SEMA/GTZ, 1995. 139 p.

PARANÁ. Secretaria de Estado do Meio Ambiente. Projeto Paraná Biodiversidade - Manual operativo. Curitiba, 2001. v. 1. 140 p.

POGGIANI, F.; OLIVEIRA, R. E. Indicadores para conservação dos núcleos de vida silvestre. Série Técnica IPEF, Piracicaba, v. 12, n. 31, p. 45-52, 1998.

PRIMACK, R. B.; RODRIGUES, E. Biologia da conservação. Londrina, 2001. 328 p.

REIS, A.; ESPÍNDOLA, M. B.; VIEIRA, N. K. Restauração de áreas degradadas: a nucleação como base para os processos sucessionais. Natureza \& Conservação, Curitiba, p. 28-36 e p. 85-92, 2003.

RIBEIRO, M. C.; METZGER, J. P.; MARTENSEN, A. C.; PONZONI, F. J.; HIROTA, M. M. The Brazilian Atlantic Forest: How much is left, and how is the remaining forest distributed? Implications for conservation. Biological Conservation. Essex, v. 142, n.6, p. 1141-1153. 2009.

SAUDERS, D. A.; HOBBS, R. J. The role of corridor in conservation: what do we know and where do we go? In: SAUNDERS, D. A.; HOBBS, R. J. (Eds.). Nature conservation 2: the role corridors. Chipping Norton: Surrey Beatty e Sons, 1991. p. 421-427. 
SILVA, T. C. Demanda de instrumentos de gestão ambiental: zoneamento ambiental. Brasília, DF: IBAMA, 1997. 33 p.

SOULÉ, M. E.; GILPIN, M. E. The theory of wilslife corridor capability. In: SAUNDERS, D. A.; HOBBS, R. J. (Eds.). Nature Conservation 2: the role of corridors. Chipping Norton: Surrey Beatty \& Sons, 1991. p. 3-8.

TABARELLI, M.; GASCON, C. Lições da Pesquisa sobre fragmentação aperfeiçoando políticas e diretrizes de manejo para a conservação da biodiversidade. Megadiversidade, Belo Horizonte, v. 1, n. 1, 2005. 